\title{
Unusual increase in reported cases of Paratyphoid A fever among travellers returning from Cambodia, January to September 2013
}

M Tourdjman (m.tourdjman@invs.sante.fr) ${ }^{1}$, S Le Hello ${ }^{2}$, C Gossner $^{3}$, G Delmas ${ }^{1}$, S Tubiana ${ }^{1}$, L Fabre ${ }^{2}$, A Kerléguer $^{4}$, A Tarantola $^{4}$,

A Fruth 5 , I Friesema ${ }^{6}$, L Thorstensen Brandal 7 , J Lawrence ${ }^{8}$, I Fisher ${ }^{8}$, M Dufour ${ }^{9}$, F X Weill $^{2}$, H de Valk ${ }^{1}$

1. Institut de veille sanitaire (InVS), Paris, France

2. Institut Pasteur, Unité des Bactéries Pathogènes Entériques, Centre National de Référence des Escherichia coli, Shigella et

Salmonella, WHO Collaborating Centre for Reference and Research on Salmonella, Paris, France

3. European Centre for Disease Prevention and Control (ECDC), Stockholm, Sweden

4. Institut Pasteur du Cambodge, Phnom Penh, Cambodia

5. Robert Koch Institute (RKI), Wernigerode, Germany

6. National Institute for Public Health and the Environment, Bilthoven, The Netherlands

7. Norwegian Institute of Public Health, Oslo, Norway

8. Public Health England, London, United Kingdom

9. Institute of Environmental Science and Research, Enteric Reference Laboratory, Wellington, New Zealand

Citation style for this article:

Tourdjman M, Le Hello S, Gossner C, Delmas G, Tubiana S, Fabre L, Kerléguer A, Tarantola A, Fruth A, Friesema I, Thorstensen Brandal L, Lawrence J, Fisher I, Dufour $\mathrm{M}$, Weill FX, de Valk H. Unusual increase in reported cases of Paratyphoid A fever among travellers returning from Cambodia, January to September 2013. Euro Surveill. 2013;18(39):pii=20594. Available online: http://www.eurosurveillance.org/ViewArticle.aspx?Articleld=20594

From January to September 2013, a marked increase in notifications of Salmonella Paratyphi A infections among travellers returning from Cambodia occurred in France. An investigation revealed 35 cases without a common source: 21 in France, five in Germany, three in the Netherlands, one in Norway, one in the United Kingdom, four in New-Zealand. Data suggest an ongoing event that should trigger further investigation. Travellers to Cambodia should observe preventive measures including good personal hygiene and food handling practices.

In the first eight months of 2013, numbers of Salmonella Paratyphi A infections among travellers returning to France from Cambodia increased markedly while several other countries also reported imported cases although to a lesser extent. Concurrently, an increase in S. Paratyphi A infections in Phnom Penh, Cambodia, starting in 2011 but with heightened numbers in 2013, was identified. Here we report mainly on the preliminary findings of the investigation of the French cases.

\section{Background}

Salmonella enterica serotype Paratyphi A only affects humans and is a cause of paratyphoid fever. Paratyphoid fever can also be caused by $S$. enterica serotypes Paratyphi B d-tartrate non-fermenting or Paratyphi $\mathrm{C}$, and remains a major cause of morbidity in countries with poor sanitation, with an estimated 5.5 million cases occurring annually [1]. In high-income countries, the majority of paratyphoid fever cases are imported from endemic regions. Transmission is faecal-oral, through consumption of contaminated food or water, as well as person-to-person. The incubation period ranges from five to 21 days depending on the inoculum ingested. Acute illness is characterised by fever and malaise; other non-specific symptoms include headaches, abdominal pain, diarrhoea or constipation, maculopapular rash and enlarged spleen. Chronic carriage can occur following acute infection. Reported case-fatality rate is approximately $1 \%$ and can be lowered by prompt use of adequate antibiotic therapy $[2,3]$. Resistance to various drugs including ampicillin, trimethoprim-sulfamethoxazole and quinolones is increasing worldwide and effective treatment requires adapted antibiotic therapy $[4,5]$. Good personal hygiene and food handling practices are the only preventive measures as there is no effective vaccine against paratyphoid infection [6].

\section{Situation in France}

In France, typhoid and paratyphoid fever have been notifiable diseases since 1903. In addition to mandatory reporting, clinical laboratories forward the isolates to the National Reference Centre for Salmonella (NRC) at the Pasteur Institute in Paris on a voluntary basis. Between 2003 and 2012, 272 cases of paratyphoid A fever were reported (annual range: 18-36), including only seven cases among travellers returning from Cambodia.

On 22 August 2013, the NRC notified the French National Institute for Public Health Surveillance (InVS) in Paris, about an unusual increase in the number of cases of paratyphoid A fever among travellers returning from Cambodia: from 1 January to 22 August 2013, 14 cases had been identified at the NRC. We initiated 
an investigation to determine the magnitude of the event and to identify potential sources of infection.

\section{Investigation of the event and results}

We defined a case as culture-confirmed S. Paratyphi A infection diagnosed in 2013 in a person who reported a travel history to Cambodia in the month prior to symptom onset. We merged data from both the NRC and the notifiable diseases surveillance system. Identified persons were contacted by phone, and demographics, clinical data, exposure history and details about their journey in Cambodia were collected using a specifically designed questionnaire.

As S. Paratyphi A is known to be a highly clonal organism that pulsed-field gel electrophoresis (PFGE) or multilocus sequence typing (MLST) techniques can hardly discriminate, the NRC focused microbiological characterisation on antimicrobial susceptibility testing and attempted to discriminate isolates by using sequencing of the Clustered Regularly Interspaced Palindromic Repeats (CRISPR) contents, as previously described $[7,8]$. We carried out antimicrobial susceptibility testing on all available $S$. Paratyphi A isolates by using the disk diffusion method, with a panel of 32 antimicrobial drugs (Bio-Rad, Marnes-La-Coquette, France). We determined the minimum inhibitory concentration (MIC) of ciprofloxacin, nalidixic acid and azithromycin using Etests (bioMérieux, Marcy l'Etoile, France), as previously described [9]. The results were then interpreted using the breakpoints of the Antibiogram Committee of the French Society for Microbiology (CA-SFM).

On 28 August 2013, the InVS sent out an alert through the European Epidemic Intelligence Information System for Food- and Waterborne Diseases (EPIS-FWD) of the European Centre for Disease Prevention and Control (ECDC) to inform other European Union/European Economic Area (EU/EEA) Member States and associated national public health institutes about the event and to query about any recent increase in their reported cases of paratyphoid A fever with a travel history to Cambodia. Countries that responded and reported cases with a travel history to Cambodia in 2013 were contacted by ECDC to obtain additional information. Moreover, ECDC used the European Surveillance System (TESSy) to compare the number of cases with a travel history to Cambodia reported in the EU/EEA in 2013 with previous years. On 28 August, when available information suggested a multinational event, the French health authorities sent out an Early Warning Response System (EWRS) message, and on 4 September, ECDC posted a rapid risk assessment on its website to alert a wider audience about the event [10].

\section{Cases notified in France}

In France, from 1 January to 20 September 2013, 21 cases of paratyphoid A fever among persons with a travel history to Cambodia in the month prior to symptom onset were reported. This represents a significant increase in the reported number of cases since only
FIGURE

Cases of paratyphoid A fever among travellers returning from Cambodia by month of symptom onset, France, 2013 $(\mathrm{n}=21)$

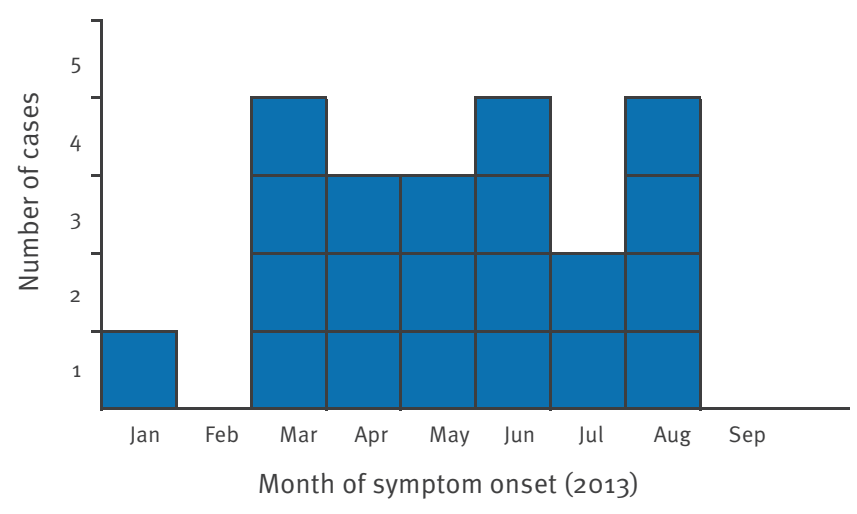

seven cases were reported between 2003 and 2012: two in 2003, three in 2004, one in 2005 and one in 2012. Dates of symptom onset ranged from 30 January to 31 August 2013 (Figure) and dates for reported travel history to Cambodia ranged from 23 January to 27 August.

Median age of infected persons was 40 years (range: 4-65 years), $67 \%$ were female and $86 \%$ were hospitalised. Clinical data were available for $17 / 21$ cases. Among patients for whom medical information was available, all presented with fever, 16/17 complained of asthenia, 13/17 had chills, 12/17 had diarrhoea, 11/17 had headaches, 9/17 had abdominal pain and 4/17 had nausea or vomiting. Median length of hospitalisation was five days (range: 1-13). All patients fully recovered. Median length of stay in Cambodia was 19 days (range: 4-81 days). Six persons experienced symptoms during their trip in Cambodia and 13 had symptom onset after their return home. For the six persons who had symptoms while in Cambodia, none sought medical attention during their trip, and median lag between arrival and symptom onset was 34 days (range: 11-61). For the 13 persons who had symptoms after their departure from Cambodia, median lag between departure and symptom onset was 12 days (range: 2-26).

One person continued to shed S. Paratyphi $\mathrm{A}$ in his urine four months after diagnosis, which caused secondary transmission to a household member who presented with bacteraemia. Illnesses occurred in tourists visiting Cambodia and travellers visiting relatives. Interviews did not identify any common exposure (such as hotel, restaurant, airline company or touristic site) that could explain all cases; $1 / 17$ interviewee only visited the city of Phnom Penh, 2/17 interviewees visited Phnom Penh and Siem Reap areas only, and 14/17 visited at least three different cities. Overall, all 17 interviewees visited Phnom Penh area, 12/17 visited Siem 
Reap area, 11/17 visited Sihanoukville area whereas other geographic areas were visited by less than 4/17 interviewees. No common exposure or common activity was identified in Phnom Penh. Fourteen of the 21 cases had solely travelled to Cambodia, whereas the remaining seven cases also reported brief travel to Thailand, Vietnam, Myanmar or China prior to symptom onset. The majority of interviewees reported consumption of at-risk food items during their trip: 15/17 ate raw vegetables or drank raw fruit juices, $16 / 17$ had drinks with ice, and 15/17 were not vaccinated against typhoid fever.

S. Paratyphi A isolates were available at the NRC for $18 / 21$ cases with a travel history to Cambodia, which accounted for $45 \%$ of $S$. Paratyphi A isolates received at the NRC as of 20 September 2013. All isolates were fully susceptible to a panel of 32 antibiotics systematically tested at the NRC, including ampicillin, trimethoprimsulfamethoxazole, fluoroquinolones and azithromycin. A unique CRISPR profile was found in all 18 isolates and belonged to the dominant profile found in the NRC CRISPR database (36/48 S. Paratyphi A isolates).

\section{Cases notified in other countries}

Following the EPIS-FWD alert sent out by the InVS on 28 August, Germany, the Netherlands, Norway, the United Kingdom (UK) and New Zealand reported cases of S. Paratyphi A infection identified in 2013 among travellers returning from Cambodia. Since 1 January 2013, 35 cases of paratyphoid A fever have been reported among travellers returning from Cambodia including the 21 cases in France, five cases in Germany, three cases in the Netherlands, one case in Norway, one case in the UK, and four cases in New-Zealand. For the EU/EEA countries this represents a significant increase since only three imported cases from Cambodia were reported in the EU/EEA in 2012 (two by Germany, one by France). No reliable data were available for 2010 and 2011. In addition to the 18 isolates tested in France, five additional isolates from other countries were available and were fully susceptible to all tested antibiotics.

Austria, Czech Republic, Cyprus, Denmark, Estonia, Finland, Greece, Hungary, Ireland, Latvia, Lithuania, Malta, Portugal, Slovenia and Sweden reported having no cases in 2013 to date.

The Table summarises the number of reported cases of paratyphoid $A$ fever among travellers returning from Cambodia in 2013, in the EU/EEA and in New Zealand.

\section{Discussion}

A marked increase in imported cases of S. Paratyphi A infections from Cambodia to France occurred from January to September 2013. Other EU/EEA countries such as Germany, the Netherlands, Norway, the UK, as well as New Zealand also reported cases, although numbers might not differ from the expected baseline range. Occurrence of cases over several months among persons with travel history in different Cambodian geographic areas and without any common exposure identified despite in depth interviews suggests that sources of contamination are persistent and potentially multiple. All 17 French interviewees have visited Phnom Penh; however, Phnom Penh is the primary point of entry for travellers in Cambodia. Available information from a referral hospital in Phnom Penh reported in this issue of Eurosurveillance by Vlieghe et al. shows a recent increase in $S$. Paratyphi A infections since March 2013 in residents of Cambodia and particularly in the Phnom Penh area [11]. This study suggests that the rate of infection is higher in Phnom Penh compared to other regions of Cambodia. However, the study site is located in Phnom Penh and therefore, recruitment bias might have affected this finding. Further investigation should be conducted to determine affected areas and to identify sources of contamination of residents of Cambodia.

\section{TABLE}

Cases of paratyphoid A fever among travellers returning from Cambodia, reported in the EU/EEA and in New Zealand, 2013 $(\mathrm{n}=35)$

\begin{tabular}{|l|c|c|l|}
\hline Country & $\begin{array}{c}\text { Number of cases } \\
\text { of paratyphoid A } \\
\text { fever }\end{array}$ & $\begin{array}{c}\text { Period of } \\
\text { reporting (2013) }\end{array}$ & Antibiotic resistance profile \\
\hline France & 21 & Jan-Aug & 18 isolates available, susceptible to all tested antibiotics \\
\hline Germany & 5 & Jan-May & 1 isolate available, susceptible to all tested antibiotics \\
\hline The Netherlands & 3 & Mar-Apr & All 3 isolates susceptible to all tested antibiotics \\
\hline Norway & 1 & Apr & Isolate susceptible to all tested antibiotics \\
\hline United Kingdom & 1 & Apr & No information available \\
\hline New Zealand & $\mathbf{3 5}$ & May-Aug & 1 isolate available, susceptible to all tested antibiotics except streptomycin \\
\hline Total & & Jan-Aug & 23 isolates susceptible to all tested antibiotics \\
\hline
\end{tabular}


According to the Cambodian Ministry of Tourism data, 121,175 French tourists travelled to Cambodia in 2012, versus 110,182 British, 72,537 Germans, 24,559 Dutch, 8,251 Norwegians, and 19,044 New Zealanders [12]. Assuming that the number of travellers to Cambodia by country of residence in $\mathbf{2 0 1 3}$ does not significantly differ from the 2012 data (available information suggests similar proportions up to May 2013), these statistics suggest that the large number of French tourists visiting Cambodia could have contributed to the predominance of French nationals among the imported cases. Taking into account the number of travellers by country, the proportions of French, British, German, Dutch, Norwegians and New Zealanders among the cases are 1 per 5,770 French travellers, 1 per 110,182 British travellers, 1 per 14,507 German travellers, 1 per 8,186 Dutch travellers, 1 per 8,251 Norwegian travellers, and 1 per 4,761 New Zealander travellers. The observed differences between countries might reflect differences in travel routes among international travellers, as well as in food habits during travel and in surveillance systems between European countries.

The strains' full susceptibility profile to all antibiotics tested appears common in southeast Asia whereas the spread of $S$. Paratyphi A strains resistant to quinolones has been described in the Indian subcontinent [13]. CRIPSR typing results suggest that CRISPR typing was not sufficiently powerful in discriminating isolates. Further subtyping, i.e. PFGE analysis with two enzymes, of available isolates is ongoing.

Additional cases might occur if the source(s) of contamination persists. However, spread within the EU/ EEA through secondary human-to-human transmission is expected to be limited: only one case of secondary transmission among household members has been documented in France so far. Clinicians in travel clinics and in infectious diseases hospitals should be alerted about the increase in the number of $S$. Paratyphi A infections among travellers returning from Cambodia. Advices about preventive measures, including personal hygiene and food handling practices, should be reinforced for travellers to Cambodia before their departure. As for other low and middle income countries, travellers to Cambodia should observe these measures and should seek medical attention as soon as possible should they present symptoms during their trip or after they returned in their country of residence. Although there is no efficient vaccine available against paratyphoid fever, travellers to Cambodia should consider typhoid fever vaccine prior to their trip, unlike the majority of interviewed travellers described in this report, as data from Vlieghe et al. also strongly suggest an ongoing increase in typhoid fever cases in Phnom Penh area [11] .

Finally, whenever possible, travellers returning from Cambodia diagnosed with S. Paratyphi A infection should be interviewed by public health authorities; their travel route in Cambodia should be detailed and information should be shared with other countries and Cambodian health authorities to help shed light on any potential source of infection.

\section{Conflict of interest}

None declared.

\section{Authors' contributions}

Mathieu Tourdjman: led the investigation in France, conducted interviews, analysed data and wrote the manuscript.

Simon Le Hello, Laetitia Fabre, François-Xavier Weill: led microbiological investigation in France and revised the article for intellectual content.

Céline Gossner: coordinated EU investigation, including rapid risk assessment and revised the article for intellectual content.

Gilles Delmas, Sarah Tubiana: conducted interviews and revised the article for intellectual content.

Alexandra Kerléguer, Arnaud Tarantola: reviewed paratyphoid A fever data available from the Pasteur Institute in Cambodia, including microbiological data, and revised the article for intellectual content.

Angelika Fruth: led investigation in Germany and revised the article for intellectual content.

Ingrid Friesema: led investigation in The Netherlands and revised the article for intellectual content.

Lin Thorstensen Brandal: led investigation in Norway and revised the article for intellectual content.

Joanne Lawrence, lan Fisher: led investigation in The UK and revised the article for intellectual content.

Muriel Dufour: led investigation in New Zealand and revised the article for intellectual content.

Henriette de Valk: supervised the investigation in France and revised the article for intellectual content.

\section{References}

1. Crump JA, Luby SP, Mintz ED. The global burden of typhoid fever. Bull World Health Organ. 2004;82(5):346-53. PMid:15298225. PMCid:PMC2622843.

2. Pegues DA, Miller SI. Salmonella Species, Including Salmonella Typhi. In: Mandell GL, Bennett JE, Dolin R, editors. Mandell, Douglas, and Bennett's Principles and Practice of Infectious Diseases. 7 th edition. New York: Churchill Livingston;2013:2887-904.

3. Heymann DL, editor. Control of Communicable Diseases Manual. 19th ed. Washington, D.C.: American Public Health Association; 2008.

4. Thaver D, Zaidi AK, Critchley JA, Azmatullah A, Madni SA, Bhutta ZA. Fluoroquinolones for treating typhoid and paratyphoid fever (enteric fever). Cochrane Database Syst Rev. 2008;(4):CDo04530. PMid:18843659.

5. Parry $\mathrm{CM}$. The treatment of multidrug-resistant and nalidixic acid-resistant typhoid fever in Viet Nam. Trans R Soc Trop Med Hyg. 2004;98(7):413-22. http://dx.doi.org/10.1016/j. trstmh.2003.10.014. PMid:15138078.

6. Newton AE, Mintz E. Infectious Diseases Related To Travel. Typhoid \& Paratyphoid Fever. Atlanta: Centers for Disease Control and Prevention (CDC). [Accessed 12 Sep 2013]. Available from: http:// wwwnc.cdc.gov/travel/yellowbook/2014/ chapter-3-infectious-diseases-related-to-travel/ typhoid-and-paratyphoid-fever

7. Fabre L, Zhang J, Guigon G, Le Hello S, Guibert V, AccouDemartin M, et al. CRISPR typing and subtyping for improved laboratory surveillance of Salmonella infections. PLoS One. 2012;7(5):e36995. http://dx.doi.org/10.1371/journal. pone.0036995. PMid:22623967. PMCid:PMC3356390.

8. Tien YY, Wang YW, Tung SK, Liang SY, Chiou CS. Comparison of multilocus variable-number tandem repeat analysis and pulsed-field gel electrophoresis in molecular subtyping of Salmonella enterica serovars Paratyphi A. Diagn Microbiol 
Infect Dis. 2011;69(1):1-6. http://dx.doi.org/10.1016/j.

diagmicrobio.2010.08.012. PMid:21146707.

9. Le Hello S, Harrois D, Bouchrif B, Sontag L, Elhani D,

Guibert V, et al. Highly drug-resistant Salmonella enterica

serotype Kentucky ST198-X1: a microbiological study. Lancet Infect Dis. 2013; 13(8):672-9. http://dx.doi.org/10.1016/ S1473-3099(13)70124-5.

10. European Centre for Disease Prevention and Control (ECDC). Rapid Risk Assesment. Unusual increase in reported cases of paratyphoid A fever among travellers returning from Cambodia. 4 September 2013. Stockholm: ECDC. Available from: http://www.ecdc.europa.eu/en/publications/Publications/ paratyphoid-fever-cambodia-rapid-risk-assessment.pdf

11. Vlieghe E, Phe T, De Smet B, Veng CH, Kham C, Sar D, et al. Increase in Salmonella enterica serovar Paratyphi A infections in Phnom Penh, Cambodia, January 2011 to August 2013. Euro Surveill. 2013;18(39):pii=20592. Available from: http://www. eurosurveillance.org/ViewArticle.aspx?Articleld=20592

12. Ministry of Tourism of Cambodia. Tourism Statistics Reports. Phnom Penh: Ministry of Tourism. [Accessed 12 Sep 2013]. Available from: http://www.tourismcambodia.org/mot/index. php?view=statistic_report\#comp

13. Crump JA, Mintz ED. Global trends in typhoid and paratyphoid Fever. Clin Infect Dis. 2010;50(2):241-6. http://dx.doi. org/10.1086/649541. PMid:20014951. PMCid:PMC2798017. 